\title{
Complementariedad ecológica y tributo en Atacama (1683-1792)
}

JORGE HIDALGO ${ }^{1}$

\begin{abstract}
Al analizar una situación prehispánica en los Andes Centro Sur, la presencia de individuos o familias establecidas permanentemente en lugares alejados de su lugar de origen o cabecera política podría ser interpretada como alguna variante del control vertical simultáneo de un máximo de pisos ecológicos (Murra 1972). Sería necesario comprobar que se trata de colonos que no han perdido sus derechos políticos en el seno de su grupo étnico original y que mantienen con éste tráfico de sus productos. Estaríamos así frente a un grupo étnico disperso, pero probablemente próspero.
\end{abstract}

Si nos trasladamos a la situación colonial hispana los mismos rasgos iniciales pueden ser interpretados como un fenómeno de desorganización, desarticulación o desestructuración del grupo étnico por efecto, principalmente, de las presiones monetarias fiscales y de los intereses particulares. El "indio de comunidad" huye de su lugar de origen para evitar los abusos de los encomenderos y luego el tributo al rey, la mita de Potosí y el sistema "de repartos" impuestos por los corregidores. Al trasladarse a otra comunidad es aceptado como forastero donde paga una tasa menor, no está sujeto a la mita de Potosí y carece de derechos políticos. Si se inserta en una hacienda puede ser agregado o arrendero y quedar vinculado a la tierra por deudas. En ambos casos procura cortar sus lazos con su comunidad de origen, la cual al reducirse el número de tributarios debe aumentar la carga de los que se quedan (Sánchez Albornoz 1978). Es un proceso de dispersión que crea marginalidad, pobreza y debilitamiento de la comunidad original.

En la situación prehispánica descrita, el propósito de la dispersión obedece a la necesidad de diversificar la producción de modo autárquico, se persigue un ideal de autosuficiencia que probablemente nunca

1 Instituto de Antropología, Universidad de Tarapacá, Arica, CHILE. se logró en su totalidad sin dejar un margen para el trueque (Murra 1978). En sus líneas más gruesas tal ideal se apreciaba incluso al nivel de la unidad doméstica, donde se producía: vestuario, alimentos, vivienda e instrumentos simples. Esta relativa autosuficiencia fue quebrada por los españoles al reemplazar la energía humana que entregaban los grupos étnicos al Estado incaico (Murra 1975, 1983), por el pago de tributos en especies y luego esas cantidades en monedas.

La búsqueda de metálico para cumplir esas obligaciones y para adquirir aquellos productos nuevos que se tornaban indispensables al aumentar la especialización empujó al campesino andino a buscar trabajo temporal en las haciendas, minerales y obrajes, al mismo tiempo que aumentaba la proporción de su producción agrícola y artesanal que era mercada.

La dispersión en busca de recursos económicos monetarios y por esta vía la ruptura con la comunidad de origen sería la esencia del proceso que habría fundido las variedades étnicas en esa especie única: "el indio colonial".

No obstante, en el corregimiento de Atacama encontramos a fines del siglo XVII un proceso de dispersión y movilidad de la población cuyas motivaciones parecen corresponder en sus líneas centrales con la presión económica monetarista, pero que en su estructura formal conserva muchos resabios de la tradición prehispánica. Este proceso perdura hasta fines del siglo XVIII cuando se produce su crisis definitiva y los atacameños residentes fuera de Atacama se integran como forasteros en los patrones de tributarios de las provincias en que residen. Creemos que nos encontramos en una situación intermedia entre el movimiento centrípeto de tipo prehispánico y la dispersión centrífuga, de tipo colonial. Estos últimos elementos pasan a ser predominantes al final del período. Dicho de otro modo, los atacameños enfrentados a la necesidad de procurarse moneda debieron en un alto porcentaje salir de su provincia. 
Se establecieron de preferencia en los bordes de la Puna desde donde podían mantener contacto con sus ayllu. Se insertaban en ingenios mineros, mayormente en haciendas e incluso en ganadería propia. Sin embargo, pagaban regularmente el tributo en Atacama por intermedio del cacique del ayllu de origen que viajaba a cobrárselo. El pago se hacía normalmente en especies. La Revisita de Atacama hecha por orden del Duque de la Palata en 1683 nos ofrece algunas pistas acerca de los mecanismos sociales, políticos, económicos y culturales que permitieron que a pesar de la intensa movilidad y enorme dispersión se mantuviera la cohesión del ayllu. Procuraremos reforzar esa información con los datos del período en que el sistema hace crisis.

Las fuentes para el estudio de este proceso no son abundantes y dejan grandes vacíos conceptuales y temporales, pero nos parece que ofrecen suficientes indicadores como para delinear las características generales señaladas. Investigación futura podrá confirmar o modificar estas observaciones, ya sea buscando antecedentes arqueológicos, históricos o mediante el trabajo etnográfico que aun puede aclarar problemas de contactos regionales.

La hipótesis de que el patrón de poblamiento de los ayllu atacameños en los siglos XVII y XVIII corresponde, en parte, a una tradición andina de manejo de recursos distantes, se fundamenta tanto en los datos históricos, que se aportan en este trabajo, como en la información etnográfica y arqueológica de sistemas de complementariedad. Entre ellos, el de doble domicilio en un patrón que combina agricultura con ganadería y trashumancia (Bowman 1942). El caso de los habitantes de Peine que controlan tierras agrícolas en Tilomonte y que deben trasladarse allí por cortas temporadas en las épocas de cultivo (Mostny 1934). Debe contabilizarse el llamado "minifundismo" o "dispersión de la propiedad", que autores contemporáneos atribuyen, equivocadamente, a la sucesión por causa de muerte (Beaulieu 1967; Hernández 1947

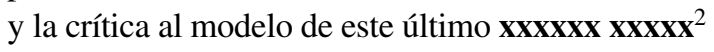
1975; Valenzuela 1969). A estos antecedentes se deben sumar las arqueológicas que sugieren colonizaciones atacameñas en el Noroeste Argentino y sur boliviano, tanto como la presencia de culturas de ese origen en los oasis de Atacama sin olvidar evidencias que pueden

2 Nota de la Editora (2009): x = Ininteligible en el original. ser explicadas por movimientos migratorios o por el tráfico de grupos que buscaron la complementariedad por intermedio del intercambio (Núñez et al. 1975). La historia de esta dinámica configuración sobrepasa largamente nuestras expectativas y las evidencias hasta ahora descubiertas.

Nuestro punto de partida documental será, no el siglo XVI, como desearíamos, sino fines del siglo XVII, cuando el corregidor Alonso de Espejo en 1683 por orden del duque de La Palata efectuó la Revisita de la provincia. No vamos a analizar este documento en extenso. Nos reduciremos a los varones casados o adultos en edad de tributar (18 a 50 años) y verificaremos dónde habían fijado su domicilio de acuerdo a esa fuente. Hemos sintetizado estos datos en cuatro cuadros.

Antes de continuar es conveniente hacer un paréntesis para recordar algunas características del área de nuestro estudio.

El Corregimiento de Atacama ubicado en la zona desértica de su nombre tiene sus centros poblados en oasis, valles y quebradas de altura con la excepción de Cobija, "puerto" del Pacífico habitado a la fecha (1683) por pescadores que hablaban una lengua distinta de aquella propia de Atacama que los estudiosos modernos han llamado kunza, término que se traduce por "nuestra".

En el área propiamente andina, Atacama se dividía en La Baja y La Alta Atacama. La separación en Alta y Baja parece corresponder a la división dualista andina ya que la altitud de San Pedro es menor que la de Chiu Chiu. La primera reconocía su cabecera en el pueblo de Chiu Chiu que agrupaba los pueblos establecidos en la hoya del río Loa, el único de los ríos del Desierto de Atacama que desemboca en el Pacífico. La Alta, encabezada por San Pedro de Atacama, era un conjunto de caseríos instalados en los oasis de altura que se ubican al este del Salar de Atacama donde desembocan los escuálidos ríos endorreicos del área. Los bosques abiertos de tamarugos, algarrobos y chañares caracterizan el paisaje de manchas verdes en un desierto absoluto. La heterogeneidad de suelos, la irregularidad de los recursos hídricos y la importancia de los algarrobos que cumplían un papel importante en la dieta y hábitos culturales atacameños favorecieron la dispersión y dificultaron la concentración demográfica (Bowman 
1946). Además de aquellos poblados, Atacama La Alta incluía algunos pueblos ubicados en el ámbito de lo que hoy es la Puna argentina, tales como Susques e Incahuasi. En el sector oriental de la Puna, Salta y Jujuy, la serranía es cortada por ríos exorreicos que crean pasadizos relativamente cortos a los bosques orientales de El Chaco y a su codiciada producción tropical (Tarragó 1983). La producción de maíz y quínoa, en tiempos prehispánicos y la del trigo en los coloniales que se cultivaba en terrazas próximas a aquellos ríos, como el San Juan, fue mayor que en la actualidad (Krapovickas 1978).

Chiu Chiu parece haber tenido más heterogeneidad cultural que San Pedro. El sector de Toconce había sufrido una colonización altiplánica que se expresa en las ruinas de chullpa (Aldunate y Castro 1981). A la fecha de la Revisita, según Espejo, todos hablaban la lengua cunza o materna, la lengua general y la española, con excepción de las mujeres que hablaban sólo las autóctonas. Es probable que cuando dice "la Gen." se refiere al quechua, pero es posible también que hablaran el aymara en consideración a los antecedentes arqueológicos y onomásticos. De modo que a fines del siglo XVII no sería extraño encontrar atacameños que hablaran los cinco idiomas mencionados: kunza, quechua, aymara, la lengua de la costa y el español.

Esta habilidad lingüística debe haber facilitado las comunicaciones con las provincias vecinas.

En el Cuadro 1 hemos anotado el número y porcentaje de los diferentes tipos de tributarios que registra la Revisita de 1683. En Atacama La Baja los tributarios presentes incluidos los hombres en edad de tributar, pero exentos por sus funciones tales como los caciques, alcaldes, cantores y sacristanes, constituían el $84.61 \%$. Ausentes permanentes, pero que pagaban la tasa a sus caciques alcanzaban al número de 12 y constituían un $13 \%$. No se registran viajeros ausentes en tránsito desde o hacia Atacama. Ausentes de los que se ignoraba su paradero o auténticos huidos alcanzaban sólo a 2.2\%. En cambio en Atacama La Alta las proporciones son notablemente divergentes. Los presentes en el $\mathrm{n}^{\circ}$ de 83 representan un porcentaje de sólo $28.8 \%$. Los ausentes que pagan tasa eran 168 , o sea $58.33 \%$. Los ausentes transitorios que pagaban su tasa en Atacama: 18, 6.3\%. Los ausentes cuyo domicilio era ignorado eran 19, $6.6 \%$ del total de 288 tributarios por la Revisita. El alto porcentaje de individuos y familias que vivían permanentemente fuera de Atacama expresado en la terminología del modelo vertical plantea el contrasentido de que la cabecera política, el núcleo, era demográficamente más débil que la periferia.

¿Cómo puede explicarse la marcada diferencia que se observa entre las dos Atacamas? Es muy difícil responder adecuadamente por ausencia de información contrastable. Espejo señala que Atacama La Baja

"es en sí infructuosa y no tiene tierras para sembrar más que la ribera de un estero, en que hacen los indios [cultivos a] modo de escaleras a fuerza de brazos y piedras. Y este es más entretenimiento que fruto, porque raro es el año que llega a madurar por las continuas heladas, mantienense los indios con las mulas, por ser todos arrieros, el estero dicho les ofrece algunos pastos, en que las tienen, eran y aún son asistentes a su provincia por la conveniencia que tenían de algunos fletes, que les venía del Reino de Chile, en que pagarían sus tasas y traían vestimentas para pasar el año" (Revisita de Atacama 1683, AGA, 9-7-7-1. f. 1; he modernizado la ortografía y desarrollado las abreviaturas).

De modo que el área de Chiu Chiu resolvía sus problemas monetarios con la arriería a lo que deben sumarse los minerales de cobre en Calama y oro en otros sitios que seguramente justificaban la presencia de los pocos forasteros que se encontraban en la provincia. La arriería y el comercio reemplazaban en Chiu Chiu el uso mútiple de recursos complementarios y distantes entre sí. Sin embargo, la categoría de "ausentes que pagan tasa" en Caspana y Chiu Chiu (26\% y $10 \%$ del total de los tributarios en cada una de esas unidades) plantea la posibilidad de algunos posibles remanentes si no son un mero resultado de la evolución colonial.

Cobija, por otra parte, es un caso especial. Los pescadores, como la revisita de Espejo sostiene, tenían lengua propia y en consecuencia los tratos que mantenían con los caciques de Atacama en el siglo XVI, descritos por Lozano Machuca (RG 1, vol. 2, 61), reflejan una situación de subordinación política y no de colonización. La costa escarpada, sin valles costeros, no ofreció a los señoríos atacameños las posibilidades que se abrieron al reino lupaqa. 


\begin{tabular}{|c|c|c|c|c|c|c|}
\hline Ayllu & $\begin{array}{c}\text { Tributarios } \\
\text { presentes }\end{array}$ & $\begin{array}{c}\text { Ausentes } \\
\text { que pagan } \\
\text { tasas }\end{array}$ & $\begin{array}{c}\text { Ausentes que } \\
\text { van y vienen } \\
\text { (de viaje) }\end{array}$ & $\begin{array}{c}\text { Ausentes } \\
\text { (no se sabe } \\
\text { dónde están) }\end{array}$ & Total & Forasteros \\
\hline Chiu Chiu & 19 & 2 & & & 21 & \\
\hline Calama & 13 & & & & 13 & \\
\hline Cobija & 18 & 3 & & 1 & 22 & \\
\hline Caspana & 27 & & & 1 (delincuente) & 35 & \\
\hline Atacama La Baja & 77 & 12 & & 2 & 91 & \\
\hline Solo & 11 & 14 & 6 & 6 & 37 & \\
\hline Sequitur & 6 & 9 & 7 & 5 & 27 & \\
\hline Soncor & 9 & 5 & 3 & & 17 & \\
\hline Solcor & 3 & 14 & & & 17 & \\
\hline Coyo y Beter & 10 & 19 & & & 29 & \\
\hline Conde Duque, Cantal y Acapana & 7 & $31^{*}$ & 2 & 5 & 45 & \\
\hline Toconao & 26 & 34 & & 2 & 62 & \\
\hline Socaire & 3 & 30 & & 1 & 34 & \\
\hline Peine y Cama & 8 & 12 & & & 20 & \\
\hline Atacama La Alta & 83 & 168 & 18 & 19 & 288 & \\
\hline Total Atacama & 159 & 180 & 18 & 21 & 379 & [10] \\
\hline
\end{tabular}

Cuadro 1. Revisita de Atacama, 1683. Categorías de tributarios. * 1a. Incluye un joven de 19, impedido, que se encuentra presente en su ayllu.

La situación de la subunidad encabezada por San Pedro es descrita por Espejo en los siguientes términos:

"La otra de Atacama La Alta es mayor y les sobran tierras en que sembrar aunque a fuerza de brazos, y son tan pocos los indios que siembran que escasamente se sustentan porque (rotura en el original) los aillos están despoblados como lo madura (rá) Vuestra Excelencia en el padrón y revisita que va con toda especificación y tengo por precisas estas ausencias, de los indios, por no tener en esta provincia en que poder conseguir el entero de sus tasas, y así se van a las convecinas donde hay algunos ingenios, a alquilarse, y los dueños de ellos en breve tiempo les arman cuenta de docientos y tresientos pesos, que nunca se ven libres de ellas $y$ de aqui resulta, el quedarse alla sin venir a sus Pueblos ni ver a sus mujeres, y cuando sus caciques los quieren sacar les sierran la puerta y dilatan las tasas, con que tengo por imposible que estos pocos presentes (quedándose los ausentes donde se hallan) puedan llevar la carga de las tasas, que haciendo la prorrata les tocará, a más de treinta pesos, en cada tercio" (Revisita de Atacama 1683, AGA, 9-7-7-la, f. lv, 2r).
La presencia de atacameños de los ayllu de San Pedro trabajando en ingenios de Lipes es registrada en 1643 cuando Inés Casma, viuda de Martín Tuctipur y madre de Pedro Viltipoco, difunto, otorga carta de perdón de muerte en favor de Martín Chico en el ingenio del Rosario de Lipes, por la muerte que éste dio a su hijo. Todos ellos eran naturales del pueblo de Soreo, de Atacama La Grande y empleados en el servicio de ese ingenio. (ANBEP Alvarez 1643, fs. 78-83, Tomo 137, Catálogo de Minas).

Sin duda la "captura por deudas" por parte de mineros $\mathrm{y}$ hacendados era un procedimiento habitual para paliar la escasez de mano de obra y retener legalmente indios de comunidad. Veremos en 1792 que la mayor parte de los atacameños en el Noroeste Argentino estaba vinculada a tareas agrícolas en tierras ajenas. No obstante, en el contenido de la misma Revisita de 1683 se agregan otras razones de la dispersión. En el ayllu Solo de Atacama La Alta se registran un ausente en Tucumán y dos en Lipes que se han retirado a los lugares referidos "por la comodidad de los pastos para sus ganados" (f. 21v). Se trataría, entonces, de ganaderos independientes en busca de recursos más estables o más ricos, pero que no rompen sus lazos con la comunidad de origen. En 


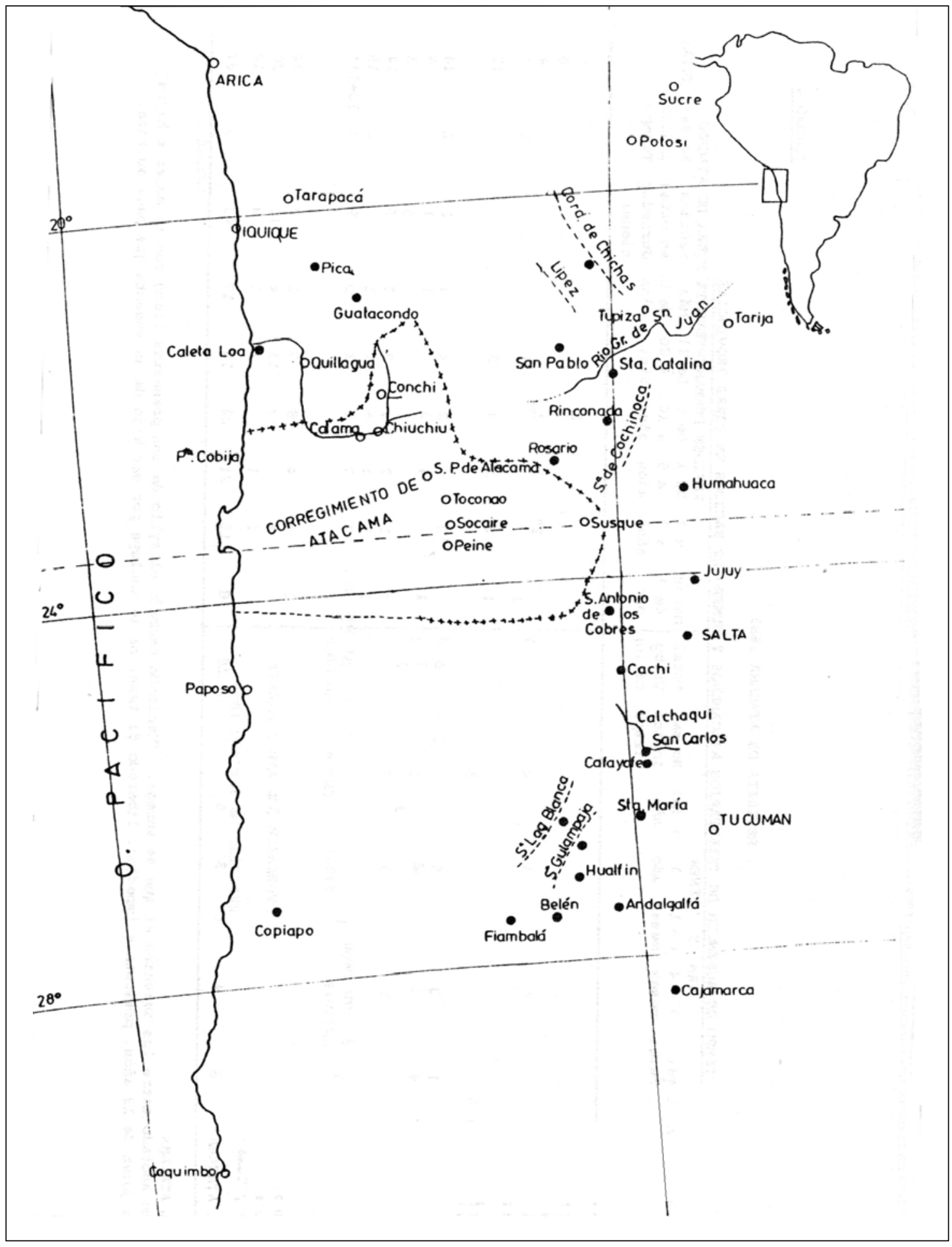

Figura 1. Lugares de residencia de atacamas ausentes que pagan tasas. 
numerosos casos menciona que los ausentes están en parajes que se reconocen por un río, esto podría ser una indicación del interés agrícola y ganadero complementario en quienes buscaban solucionar las demandas monetarias fiscales.

Que los productos agropecuarios jugaban un papel en los tributos y por esa vía, en la complementariedad ecológica parece indudable a la luz del informe de don José Agustín de Arze, revisitador de Atacama 100 años más tarde, 1786-87. Este funcionario, que conoció bien Atacama, destaca los extraordinarios sacrificios que debían realizar los caciques para cobrar los tributos de los atacameños que residían en la Intendencia de Salta. Los caciques tardaban ocho días en cruzar la cordillera y luego debían recorrer las enormes distancias que separaban sus casas (se repartían entre Jujuy, Salta, Tucumán y Cajamarca). Agrega:

"Aunque todos o la mayor parte de los tributarios pagan su respectiva asignación en frutos de labranza, o en otras especies de Industrias, tienen asentados con los cobradores el equivalente precio o su estimación, y así nunca quedan perjudicados, y más bien los caciques sufren algún atraso en la demora, que suelen padecer en darle expendio para cubrirse del dinero que anticipan regularmente en muchos casos, y especialmente por aquellos que no tienen mayor posible, y sobre este supuesto no hay entre ellos la discordia que podía motivar otra mala versación" (Hidalgo 1978-79).

Esos frutos de labranza y artesanías con valores monetarios definidos eran llevados directamente a Atacama o vendidos o trocados por los caciques en la ruta. El hecho que los caciques anticiparan dinero significa que ellos marcaban esos frutos y que la autoridad fiscal recibía sólo monedas o también recibían productos mercables. ¿Qué productos llevaban los caciques a Atacama y de dónde salía el dinero para pagarlos? Nada sabemos aún de todo esto, con excepción de que el corregidor de 1750 aceptaba el pago del tributo en trigo. Cabe preguntarse si las cabezas políticas de los ayllu se limitaron a extraer excedentes de sus tributarios o llevaban algunos presentes de la comunidad, de modo de suavizar la exacción fiscal $\mathrm{y}$ asegurar los lazos de solidaridad indispensables para que esa institución se perpetuara en el tiempo. Lamentablemente las fuentes ubicadas hasta ahora no permiten responder estas preguntas.

Es conveniente volver al patrón de dispersión antes de analizar su disolución a fines del siglo XVIII.
Como hemos visto en el Cuadro 1 la mayor parte de los ayllu de Atacama si bien tenían localización geográfica, desde el punto de vista social eran estructuras notablemente dispersas, especialmente los del sector de San Pedro. Donde estaban esos tributarios ausentes de mucho tiempo que pagaban su tasa regularmente. En el Cuadro 2 hemos anotado los datos que nos ofrece la revisita de 1683. Como puede verse el Corregimiento de Lípez era la provincia que atraía el mayor número de ambas Atacamas. Seguía en importancia para La Alta la jurisdicción del Tucumán (particularmente en el río de San Juan). Seguían en número los 29 atacameños instalados en Chichas (17.26\%). El resto en números de 2 a 3 se distribuían entre Guatacondo, Pica y Loa en la Jurisdicción de Tarapacá, además en Chile y Sinti. En sólo tres casos no se señala el lugar de residencia.

Si se observa un ayllu en particular como Conde Duque, Cantal y Acapana sorprende su extraordinaria dispersión y el escasísimo número de tributarios presentes. De los siete presentes cuatro eran autoridades indígenas, quienes por sus funciones debieron ausentarse con frecuencia, los otros tres eran un ciego, un soltero de 22 años y un chileno (?). En consideración a que la revisita registra 45 hombres cabezas de familia y solteros que debían pagar tributo, en este caso solo el $15.5 \%$ tenía su residencia en Atacama. La dispersión geográfica puede apreciarse en detalle en el Cuadro 2.

En el Cuadro 3 hemos anotado la dispersión de los ausentes que van y vienen y que coinciden con Lípez, Tucumán, Chichas y Chile. Seguramente este listado es corto o inferior a la realidad ya que no registra el movimiento de los arrieros de Chiu Chiu, pero también ayuda poco para suponer que contribuían a mantener la comunicación entre los ayllu y sus tributarios distantes, particularmente en el caso del ayllu citado: Conde Duque. En cambio, en el caso del Sequitur estos viajeros pudieron colaborar en la tarea de mantener lazos directos entre las autoridades y los tributarios o entre éstos y sus familias.

En el Cuadro 4 he anotado el tiempo de ausencia tanto de los tributarios en viaje como de aquellos que residían permanentemente fuera de la provincia en 1683. El número más alto dentro de las categorías anotadas son los nacidos en otras jurisdicciones que alcanzaban 29.34\% del total de ausentes que pagaban tasa en Atacama La Alta. En otros términos, $17 \%$ del total de los tributarios de Atacama La Alta, en 1683, había nacido fuera de la provincia. Más de 56\% de los 


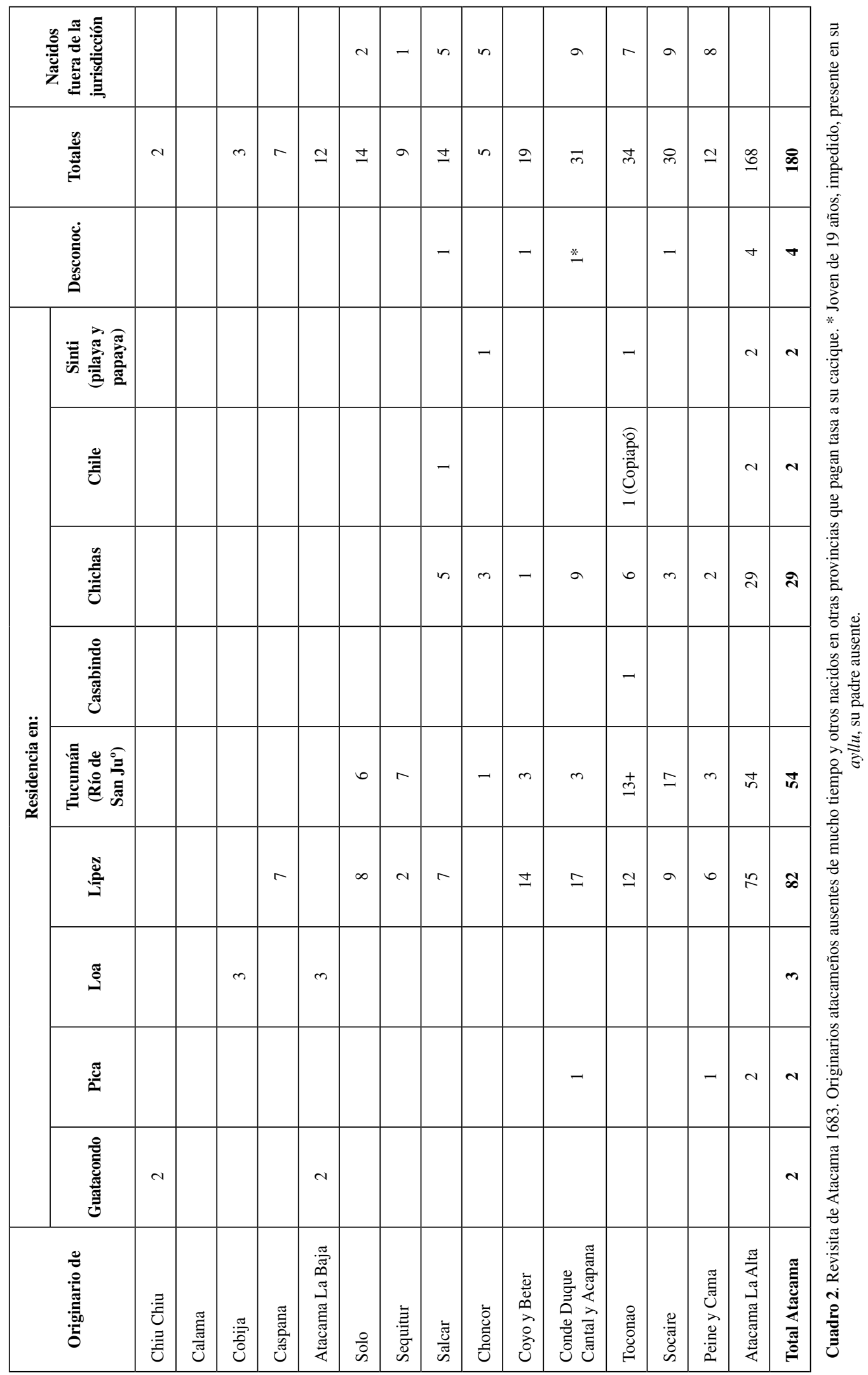




\begin{tabular}{|l|c|c|c|c|c|}
\cline { 2 - 6 } \multicolumn{1}{c|}{} & $\begin{array}{c}\text { Chichas } \\
\text { R. San } \\
\text { León }\end{array}$ & Lípez & Chile & $\begin{array}{c}\text { Tucumán } \\
\text { Río de } \\
\text { San Ju }\end{array}$ & Total \\
\hline Solo & 3 & 2 & 1 & & \\
\hline Sequitur & & 4 & 2 & 1 & \\
\hline Soncor & & 1 & & 2 & \\
\hline $\begin{array}{l}\text { Conde } \\
\text { Duque, } \\
\text { Cantal y } \\
\text { Acapana }\end{array}$ & & & 2 & & \\
\hline Total & $\mathbf{3}$ & $\mathbf{7}$ & $\mathbf{5}$ & $\mathbf{3}$ & $\mathbf{1 8}$ \\
\hline
\end{tabular}

Cuadro 3. Revisita de Atacama 1683.

Ausentes que van y vienen.

ausentes que pagaban tasa habían dejado la provincia hacía más de 11 años o había nacido fuera de ella. Considerando estos largos lapsos temporales en las historias vitales y este patrón de uso de recursos múltiples, a días y semanas de camino, cabe preguntarse cómo se mantenía la cohesión y solidaridad de estos grupos, ¿cómo podían seguir perteneciendo al ayllu individuos que habían nacido en otras provincias y que vivían permanentemente en ellas?

Sin duda los caciques, viajeros o arrieros jugaron un papel en la sobrevivencia de los ayllu, aun cuando, como hemos señalado, es difícil atribuirles a ellos toda la responsabilidad. Todo lazo tiene dos extremos y el hombre o grupo familiar que dejaba Atacama también podía intentar mantener esos vínculos o cortarlos. Podría tener interés en mantenerlos para conservar sus derechos a aguas y tierras en Atacama, derecho que conservaron hasta fines del siglo XVIII. Pero si este derecho no era ejercido, ¿cuál podría ser el interés en cumplir con obligaciones sin recibir nada a cambio? No parece haber sido ésta la situación a fines del siglo XVII. En un buen número de casos (33.33\% de los ausentes que pagan tasa) el hombre ha dejado la provincia pero su mujer o alguno de sus hijos está presente, disfrutando de los recursos otorgados por el ayllu o heredados de familiares.

El interés económico no era el único que motivaba el interés de los tributarios para seguir ligados al ayllu del cual eran originarios, también parece haber jugado un papel significativo la tendencia a la endogamia. Sólo 24 de los 168 tributarios ausentes que pagaban tasa se habían casado con forasteras o mujeres que no pertenecían originalmente al ayllu, o sea sólo 14\% de los migrantes se había casado con forasteras. El número de solteros y viudos era de 48 , o sea $28.57 \%$. Los casados con originarias eran 96 y constituían el 57.14\% del total de los 168 tributarios ausentes que pagaban tasa en Atacama La Alta.

Seguramente un conjunto de rasgos culturales entre ellos la lengua, vestimentas, festividades, sistema de parentesco, el sistema de autoridades y de intercambio, además de los intereses económicos mencionados, tierra, agua, pastos, etc. que se constituían en posibilidades o seguros contra la extrema pobreza contribuyeron a conservar la cohesión de los ayllos a pesar de la dispersión y de las presiones coloniales que hemos descrito.

No obstante, un factor que no debe ser menospreciado en la conservación de este patrón del poblamiento disperso fue la aceptación y el conocimiento que tenían de él las autoridades fiscales y por esta vía el sistema recibió refuerzo legal. Al menos desde la revisita de Espejo, las autoridades asumieron que los indios atacameños debían seguir pagando su tributo donde quiera que se encontrasen. Espejo en su informe expresa el temor de que Atacama se despoblace si se impedía la arriería en Chiu Chiu y si los ausentes eran empadronados como forasteros en los lugares de residencia. En este último caso los residentes en Atacama tendrían que pagar tasas desmesuradas, superiores a 60 pesos anuales por tributario. Se autorizó entonces legalmente a corregidores y caciques de Atacama a seguir cobrando tributos fuera de la provincia y ser tolerados por las autoridades de las otras jurisdicciones. Quien no pagara tributo podía ser forzado a hacerlo, se le podía hacer volver a Atacama y encarcelarlo. La Revisita de 1752, hecha por el corregidor Manuel Fernández Valdivieso, confirma esta situación en varios casos, un ejemplo es "Joseph Gregorio de 20 años, soltero, habiéndolo traido de Salta se volvió a huir" (ayllu Conde Duque, Revisita de 1752, AGNA 9-7-7-1). Otro es Francisco, de 54 años, del ayllu Conde Duque, residente en Copiapó "a quien han tenido en este pueblo en la cárcel en varias ocasiones por no querer pagar su tasa cuando tenía edad para ello" (ayllu Conde Duque, Revisita de 1752, AGNA 9-7-7-1).

En la Revisita de 1752 no se encuentra la categoría "ausentes que pagan tasa", por cuanto éstos normalmente están incluidos entre los tributarios originarios. También parece ser el caso de algunos de la categoría "ausentes", pero de preferencia se reserva esta última categoría para aquellos que han huido, de allí que algunas destinaciones poco populares de 1683 aumentan en 1752, tales como Copiapó y Coquimbo en el reino de Chile para tributarios de 


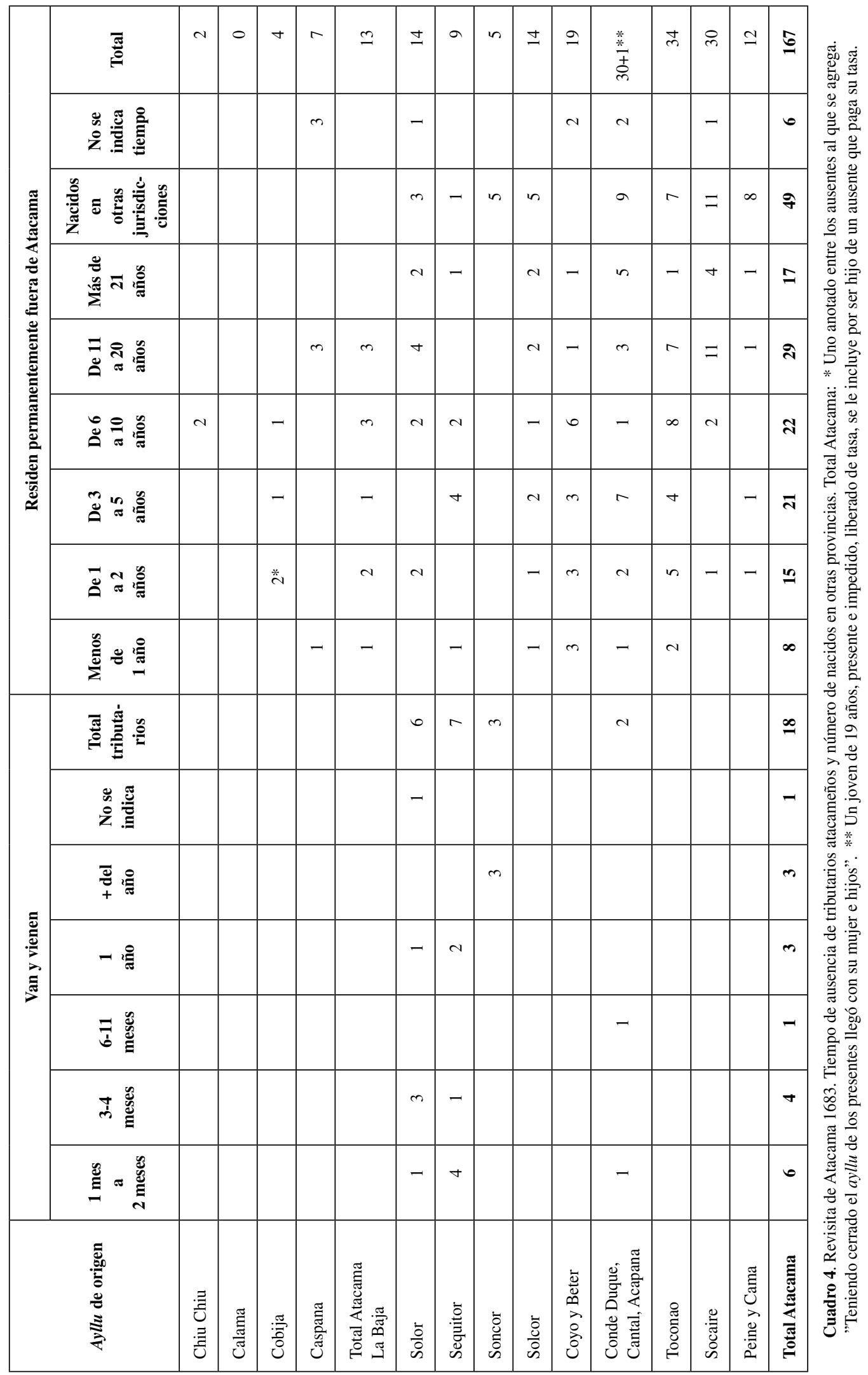


Atacama La Alta y Guatacondo en Tarapacá para los tributarios de La Baja. Un análisis detallado de estos cambios no lo haremos en esta ocasión pero el punto que nos interesa destacar es que no hay ni cuestionamiento ni extrañeza frente a originarios de Atacama que residen en otras provincias. Un caso que resulta sorprendente para nosotros, pero no para el revisitador, es que el cacique del ayllu Soncor "asista", es decir, resida en "La Laguna Blanca, jurisdicción de Salta" y no el pueblo de Atacama que lleva el nombre del ayllu.

Sin embargo, en 1750 hay claros indicios de que el sistema estaba en crisis y que surgía una cuestión de identidades. Los revisitadores de Jujuy, Juan Antonio Ramón de Herrera y Juanchín Romualdo Velásquez, se reunieron en el pueblo de Cochinoca, en marzo 20, de 1750, con el alférez don Juan de Araya, vecino de Atacama, quien en representación del corregidor don Manuel Fernández Valdivieso venía a recaudar "los tributos de los indios, que consta por una memoria" y una solicitud que en 1730 había hecho el corregidor de Atacama al gobernador del Tucumán para que excluyese del padrón de su jurisdicción a los indios de Atacama. Pero en los 20 años pasados se habían producido "continuos pleitos entre los cobradores y los gobernadores de ambas jurisdicciones" sobre quiénes debían pagar. De esto se beneficiaban los indígenas para "no pagar ni a una ni otra parte los Reales Tributos a su Majestad más de cincuenta indios que se hallan en esta jurisdicción por la contienda de dichos cobradores". En consecuencia, los revisitadores ordenaban:

"y para que se aclare los que son y pertenecen a cada jurisdicción y atendiendo al grave perjuicio que recibe su Majestad, mandamos al referido Dn. Juan de Araya teniente de corregidor y al Gobernador y cacique del partido del Río de San Juan Dn. Martín Caucota, comparezcan con sus personas en el pueblo de la Rinconada al tiempo y cuando se principien los padrones a dicho ayllo para que con toda claridad conste en adelante los que pertenecen a cada jurisdicción."

El 2 de mayo de 1750 se revisó el:

"Padrón de los indios originarios oriundos de la Provincia de Atacama, a quienes el gobernador Dn. Martín Caucota debe cobrar las tasas arreglándose a las reales provisiones del archivo de dicho Atacama de la Real Audiencia de la Plata obedecidas por los señores Gobernadores de la Provincia de Tucumán y sus subalternos; año de mil setecientos y cuarenta y ocho."
Seguía una lista de 20 tributarios y un reservado. Otros nueve seguían a continuación que se excluían de ese padrón "por haber dado prueba legítima" de no pertenecer a él. Pero "en este estado compareció don Martín Caucota y probó ser Lorenzo Sánchez y sus hijos Domingo y Pascual de dicha Provincia de Atacama", los que fueron sumados a los 20 anteriores.

Es evidente que la distinción entre indígenas de una u otra provincia ya no era nítida y que su pertenencia o inclusión en el padrón de tributarios no era voluntaria sino que forzada por la autoridad cacical y refrendada por la ley hispana.

Los corregidores, sin duda, procuraron usufructuar de este conocimiento para sus fines particulares. ¿De qué modo el reparto forzoso de mercaderías se podía realizar con esta distribución de la población? Probablemente los caciques sufrieron más directamente la presión del corregidor que los tributarios, quienes siempre tenían la posibilidad de ocultarse, huir u otras formas de resistencia. Ejemplo de lo intolerable que se tornaban las exigencias que debían sufrir estos caciques encontramos en las dos Atacamas. En Chiu Chiu, Antonio Bernardo Echeverría, viudo de 33 años, con cuatro hijos huyó a Copiapó "por haberlo elegido de cacique, arrojó el padrón y se fue". En las cuentas de Manuel Fernández Valdivieso, figura el cacique del pueblo de Toconao Francisco Roque, a quien lo quitó del cargo por deber 187 pesos 5 reales de tributo "sin esperanza de cobrarlos por no tener bienes ningunos". En realidad todos los bienes de este cacique habían sido expropiados por el corregidor (Hidalgo 1982). No son los únicos ejemplos, el mismo corregidor incluyó a otros dos caciques que le debían entre 100 y 160 pesos sin esperanza de cobrarlos y se queja de la falta de individuos "de conveniencia" que den garantía con sus bienes de los dineros a recaudar.

Si era difícil cobrar los tributos, mayores dificultades debieron encontrarse para exigir pagos extras, para ello debió recurrirse a la violencia, en diferentes formas, lo que produjo como consecuencia un mayor número de indios que huían de Atacama, abandonando sus tierras y familias, o tributarios que pagaban sus tributos a disgusto. De este modo la visita del cacique extractor al Noroeste Argentino dejó de ser la ocasión de un encuentro entre parientes para transformarse decisivamente en el representante de la demanda de pagos que resultaban cada vez más injustos.

No obstante la solidaridad entre atacameños "ausentes" y sus autoridades étnicas no había desaparecido del todo en 1775 cuando se produjo la rebelión en 
Incahuasi y el corregidor de Atacama debió huir al Tucumán. Desde allí intentó reunir tropas para regresar y castigar a los rebeldes, pero éstos, que recibían información de los campesinos atacamas, que habitaban en la zona donde se organizaba el contraataque, amenazaron con abandonar masivamente la provincia; el corregidor debió abandonar sus proyectos (Hidalgo 1982).

En abril de 1791 el Dr. don Vicente Anastasio de Isasmendi, cura y vicario del beneficio de Calchaquí, solicitó al gobernador intendente, en Salta, que los indios atacameños que residían en su provincia fuesen empadronados en ella y pagaran allí sus tributos, para recibir de ese modo el sínodo que le correspondía a él que los atendía en lo espiritual y no al cura de Atacama. Señala:

"de muchos años a esta parte residen en aquella mi doctrina (Calchaqui) indios que tributan a la Provincia de Atacama, los más de ellos nativos en aquel distrito y descendientes de los que se trasladaron sujetos enteramente en lo espiritual a la citada mi doctrina; y como desde su establecimiento en ella jamás se ha consignado al párroco el correspondiente sínodo, sin duda por no haberse éstos en las pasadas revisitas empadronado como corresponde y demanda su continua residencia."

En su favor argumenta Isasmendi: "pues si es digno el jornalero de reportar su extipendio, si el que sirve el altar es forzoso viva de aquel mismo altar en quien emplea todos sus desvelos...". "A estos postulados agrega que los indios de Atacama sufren continuamente las recaudaciones de tributos de la Intendencia de Potosí y como para cobrarles debían cubrir tan enormes distancias, los costos se los cargaban a los pobres indios de lo que resultaba que pagaban tributo duplicado en relación al resto de los naturales. Habían adquirido por esto terror de los recaudadores. Antes de que llegase el tiempo en que esos comisionados pasaban a la provincia huían a los montes para evitar el cobro. Por otra parte, por no ser tributario de Calchaquí, estos atacameños de Salta debían pagar los derechos parroquiales como: "puramente soldados". Esto parece indicar que estaban sujetos a un pago más alto que los naturales de la provincia (AGNA 9-30-4-9, Testimonio del expediente formado sobre el empadronamiento en Salta de los indios del partido de Atacama, revisitados en aquellas jurisdicción; también notas sobre este expediente publicadas por Murra en Estudios Atacameños 2).

La Real Hacienda de Salta consideró que la petición era "justa y arreglada a derecho" y en consecuencia recomendaba empadronar en Salta a los atacameños que residían en esa provincia.

Otro informe que daba respuesta a la solicitud de Isasmendi, escrito por los ministros Gueme y Rabaza, recordaba el artículo 120 de la Real Ordenanza de Intendentes establecía que "deben ser empadronados en cada partido de provincia todos los habitantes sujetos a esta contribución que residen en ellas." Concluía que estando los Atacamas en Calchaquí, allí debía hacerse un padrón separado de ellos, así satisfacerían sus pagos, sin molestias de los pobladores de Atacama. Si eran dados de baja en Atacama y se les cobraba en Salta no sufriría el Real Erario. Reflexionaban que si bien "en Atacama los indicados indios corren con el nombre de originarios porque allí tienen tierras propias ya en Calchaquí deben apreciarse como foráneos y en esta clase se les deberá cobrar lo mismo que pagarían en su antigua provincia”. Opinaban que desterrar a los Atacamas de Salta les traería perjuicio por el "incomparable mejor terreno que ocupan del que dejaron sus antepasados" (AGNA 9-30-4-9).

El expediente en cuestión fue enviado a Potosí y allí se solicitó la opinión del subdelegado del partido de Atacama, quien se mostró partidario de segregar del padrón de su provincia a los residentes en Salta, aunque sus razones diferían de los funcionarios de esa Intendencia. En consideración al beneficio del Real Erario era partidario de poner la medida en ejecución a la brevedad. Su punto de vista reflejaba las opiniones de los caciques de Atacama. Argumentaba que entre Salta y Atacama existen más de 200 leguas,

"la mayor parte despoblados y cordillera y que siendo indispensable a los miserables caciques el transporte de uno a otro territorio en cada tercio se ven en la precisión de viajar con las inclemencias, trabajos y crueles hambres que ofrecen aquellos desiertos y el corto viático que para este fin se les tiene asignado.

...y cuando era de creer que inmediatamente su arribo a aquellas partes de Salta lograsen el efecto de su laborioso viaje con la pronta satisfacción de las tasas, sucede que los naturales tributarios engreídos con el abrigo de hallarse en ajena jurisdicción y sacudidos del yugo de la subordinación, les dilatan el pago o ya ocultando sus individuos, o ya procurando inferirles agravios y extorsiones que les intimiden hasta llegar al extremo de perseguirlos a lazo y cuchillo" (AGNA 9-30-4-9, f. 8r).

Terminaba el subdelegado de Atacama quejándose que de este modo les era muy difícil a los caciques 
cobrar el total de lo adeudado y se veían obligados, junto al subdelegado, a reponerlo de su propio peculio. Por esto ya no se encontraban en Atacama varones que quisieran aceptar de libre voluntad los cargos de caciques cobradores. En consideración a lo anterior, recomendaba extender la proposición del intendente de Salta a los "pueblos nombrados Fiambalá, San Carlos, Santa María y Belén" (AGNA 9-30-141-9, 9r).

De acuerdo entonces a las opiniones de las autoridades españolas de Salta y Atacama la conservación del sistema de empadronamiento por el lugar de origen, no por el de residencia, ya no resultaba satisfactorio para nadie y por el contrario se había tornado para todos en una carga difícil de soportar. Incluso el cacique principal de Atacama y su "Segunda" saludaban con entusiasmo la posibilidad de la separación, señalaban en una de sus cartas: "ya que la piedad del señor intendente de esta provincia se ha dignado separar nuestros mayores enemigos que se hallan avencidados en la jurisdicción de Salta", solicitaban una nueva revisita (AGNA 9-30-4-9, f. 36v).

Creo que para el tema de este trabajo es innecesario reiterar los argumentos legales y sociales que interponen los funcionarios del fisco a favor o en contra de innovar los padrones de Atacama y Salta. El hecho es que la medida se puso en práctica antes de su completa aprobación. En la Revisita de Atacama de 1792, el subdelegado Benito Antonio de Goyena, por orden del intendente de Potosí citó a los caciques para formar:

"una razón puntual de los indios de este partido que se hallan ausentes en la provincia de Salta con el objeto de confrontarla con el testimonio de la revisita que nuevamente debe actuarse en aquella jurisdicción de las familias que existen en ella... comparezcan ante mí gobernadores, segundas, caciques enteradores de la doctrina de esta capital y bajo la solemnidad del juramento declaren y manifiesten todos y cada uno de por sí los indios que constan en sus respectivos padrones domiciliados en la Jurisdicción de Salta ausentes de este partido con expresión de nombres, edades, lugares de su residencia y por el orden que guarda la última revisita actuada en el año de 1786" (AGNA, 13, 19, 1, 1, f. 78).

Siguen las declaraciones de los caciques de los seis ayllu de San Pedro y de Toconao, Soncor, Peine y Susques, con los detalles solicitados. La información aparece ligeramente corregida más adelante en la misma revisita. De acuerdo a uno y otro resumen el número de tributarios residentes en Salta, sería el siguiente:

\begin{tabular}{|l|l|r|r|}
\hline \multirow{2}{*}{ Ayllu } & \multicolumn{2}{c|}{$\begin{array}{c}\text { Indios } \\
\text { tributarios } \\
\text { ausentes }\end{array}$} \\
\cline { 3 - 4 } & f.88r. & f.108v. \\
\hline Conde Duque & Dn. Pedro Gerardo Liquitay & 15 & 19 \\
\hline Sequitor & Dn. Andrés Chávez & 4 & 4 \\
\hline Coyo & Dn. Martín Apares & 14 & 15 \\
\hline Solor & Dn. Juan Manuel & 14 & 14 \\
\hline Beter & Dn. Agustín Lucas & 13 & 13 \\
\hline Solcor & Dn. Santos Manuel & 13 & 13 \\
\hline Toconao & Dn. Joseph Mathias & 6 & 7 \\
\hline Soncor & Dn. Martín Matheo Fabián & 24 & 26 \\
\hline Socaire & Dn. Martín Matheo Fabián & 41 & 42 \\
\hline Peine & Dn. Bernardo Lázaro Reyes & 41 & 46 \\
\hline Susques & Dn. Thomas Manuel Puca Puca & 38 & 34 \\
\hline Total de tributarios ausentes & $\mathbf{2 2 3}$ & $\mathbf{2 3 3}$ \\
\hline
\end{tabular}

Cuadro 5. Tributarios ausentes en Atacama.

Se resumen también en la revisita los lugares donde estos tributarios residían y su número:

\begin{tabular}{|c|c|c|c|}
\hline Lugares & $\begin{array}{c}\mathrm{N}^{0} \text { de } \\
\text { tributarios }\end{array}$ & Lugares & $\begin{array}{c}\mathrm{N}^{0} \text { de } \\
\text { tributarios }\end{array}$ \\
\hline Santa María & 28 & Fiambala & 22 \\
\hline Laguna Blanca & 18 & San Carlos & 7 \\
\hline Calchaquí & 30 & Andargala & 2 \\
\hline Cachi & 4 & Angastaco & 5 \\
\hline San Antonio del Cobre & 10 & Culampaja & 5 \\
\hline Rinconada & 1 & Guandacal & 1 \\
\hline Bolsón & 14 & Tolombón & 2 \\
\hline Cafayate & 3 & Gualfin (Hualfin) & 1 \\
\hline Tacuil & 7 & Jacton & 1 \\
\hline Belera & 11 & Pucará & 3 \\
\hline Concho & 06 & Pacta & 1 \\
\hline Cajoncillo & 1 & Cajón & 7 \\
\hline Cajones & 13 & Salta & 2 \\
\hline Payogasta & 1 & Vicuña Pampa & 3 \\
\hline Palo Blanco & 1 & Suracatao & 1 \\
\hline Loconte & 3 & Tolar & 1 \\
\hline Táctil (Tastil) & 7 & Frume Arco & 1 \\
\hline Rosario & 1 & Capillas & 1 \\
\hline Altos de Tonco & 1 & Cortaderas & 1 \\
\hline Jujuy & 1 & Pampa Grande & 1 \\
\hline \multirow[t]{2}{*}{ Guasamayo } & 1 & Uturunco Guasi & 1 \\
\hline & & Frontera & 2 \\
\hline Total tributarios & 162 & & 71 \\
\hline
\end{tabular}

Cuadro 6. Tributarios ausentes en Salta. 
La suma total coincide con la del segundo listado y señala la revisita que son 43 parajes "en los que al presente residen los doscientos treinta y tres tributarios que se han segregado de las parcialidades de este su origen, Atacama, junio 18, 1792" (AGNA 13-19-1-1, f. 109v.). Cabe destacar que la mayoría de los lugares mencionados coinciden con sitios arqueológicos de los períodos Medio y Tardío del Noroeste Argentino. Esta coincidencia entre tradición prehispánica de poblamiento y los establecimientos coloniales deberá ser evaluada por los arqueólogos de esa área en orden a determinar si existen evidencias de colonizaciones atacameñas tardías en ese período o se trata de un fenómeno surgido en el Período Colonial. En el mapa puede verse la distribución de estos lugares.

Toda la documentación de fines del siglo XVIII se concentra sobre los atacameños en Salta y Tucumán, nada se dice de aquellos que habitaban en Lípez y Chichas, las otras dos provincias que concentraban un número importante de tributarios ausentes de Atacama en 1683.

Nos queda finalmente la pregunta: ¿cómo se insertaban productivamente en esos lugares de lo que hoy es el actual Noroeste Argentino, los atacameños a fines del siglo XVIII? Afortunadamente podemos responder en detalle esta pregunta ya que hemos ubicado en el Archivo General de la Nación Argentina el:

"Padrón de los indios originarios de Atacama, que residen en el beneficio y anexos de Calchaqui, a quienes habiéndoseles preguntado por mí el revisitador, si tenían en su origen tierras de comunidad dijeron los más de ellos la tenían, pero estériles y sin agua, por cuya razón se habían pasado al dicho valle y curato, para poderse sustentar y en este concepto se hace la siguiente matrícula" (AGNA, siglo XVIII, 17; 2, 1, Revisita de Salta 1791).

El resumen que se hace se muestra en el Cuadro 7:

\begin{tabular}{|c|c|c|c|c|l|c|c|c|c|}
\hline Reserv. & Niñas & Viudas & Solteras & Casadas & \multicolumn{1}{|c|}{ Curatos } & Tribut. & Ausentes & Próx. & Niños \\
\hline 17 & 45 & - & 14 & 57 & Calchaquí & 69 & 1 & 3 & 65 \\
\hline 2 & 15 & 1 & 6 & 20 & Sta. María & 28 & - & 3 & 6 \\
\hline 3 & 15 & - & 4 & 18 & Belén & 25 & - & 2 & 3 \\
\hline 2 & 2 & - & 2 & 4 & Fiambalá & 4 & - & 2 & 3 \\
\hline $\mathbf{2 4}$ & $\mathbf{7 7}$ & $\mathbf{1}$ & $\mathbf{2 6}$ & $\mathbf{9 9}$ & Total & $\mathbf{1 2 6}$ & $\mathbf{1}$ & $\mathbf{1 0}$ & $\mathbf{7 7}$ \\
\hline
\end{tabular}

Cuadro 7. Tributarios de Su Majestad del origen de Atacama.

Los revisitadores de Salta ubicaron 441 personas y 126 tributarios (que después se redujo a 111), cifra muy inferior a los 223 o 233 tributarios registrados en Atacama. Es evidente que en Salta existía interés en "ocultar" indígenas y separarlos del control fiscal. La Contaduría General de Retasas destaca que la diferencia se debe a que ni en Salta (Calchaquí) ni en Catamarca (Sta. María, Belén y Fiambalá) se solicita a los dueños de haciendas, chacras y minas que declaren el número y origen de los forasteros que trabajaban para ellos (AGNA 9-30-4-9, Expediente sobre empadronamiento en Salta de los indios de Atacama, informe de la contaduría de retasas y el tribunal de cuentas a los señores de la Junta Superior, 1806).

En relación a Salta y a la situación específica de los atacamas en ella, el informe citado analiza lo siguiente:
"La contaduría ha reconocido con especial atención, así el empadronamiento general que se hizo en el distrito de la ciudad de Salta, el año pasado de 1791, como el que por separado se mandó hacer de los Indios de Atacama en el propio tiempo; y advierte que de los 582 tributarios útiles que es el total de la matrícula principal y 67 reservados por su edad, que unidos suman 649 por la parte más corta las dos tercias partes son indios de los partidos interiores del Reino, ocupados los más de ellos de arrenderos, otros agregados y algunos a conchavo en las chacras y estancias vecinas de aquella ciudad.

En el que por separado se hizo de los indios de Atacama avecindados en las haciendas del distrito del curato o repartimiento de Sn. Pedro Nolasco de Calchaqui en el partido de Salta, se matricularon 86 individuos los 69 tributarios útiles y los 17 mayores de edad y de este crecido número tan solamente dos 
de ellos gozan tierras, el uno por matrimonio que es Juan Ignacio Valencia, casado con Justa Cañisares que vive en las tierras de esta nombrada Seclantas, y en el anejo de Sn. Antonio Pablo Fabián que las tiene propias y los demás subsisten de arrenderos y agregados de aquellos hacendados.

Esta misma ocupación tienen, así los 57 tributarios útiles como los 7 reservados del Partido de Atacama que se empadronaron en el distrito de la ciudad de Catamarca y puede decirse que la provincia de Salta es el asilo de los fugitivos como que en los vecinos de ella hayan toda protección y amparo para vivir con la libertad que apetecen apartados de las justicias y el régimen de sus curas y exentos de los servicios de su obligación en los pueblos de su origen" (AGNA, siglo XVIII, 17-2-1, Revisita de Salta 1791).

La situación descrita en estas citas no califica un sistema de complementariedad con control múltiple de recurso. Se trata de la descomposición de los remanentes de aquel sistema durante el período colonial, es decir de desvinculación con la comunidad de origen y de readscripción a un propietario privado de tierras agrícolas o de pertenencias mineras. Los dos casos excepcionales que lograron tener tierras propias en Salta marcan aún más la ausencia de cualquier control comunitario sobre ellos.

Agradecimientos Este trabajo ha sido escrito gracias a los fondos aportados por la Dirección de Investigaciones de la Universidad de Tarapacá al proyecto: "Las sociedades indígenas de los corregimientos de Arica, Tarapacá y Atacama...", a las facilidades que se me otorgaron en el Archivo Nacional de la Nación Argentina, Buenos Aires, y Archivo Nacional de Bolivia, Sucre, de donde proviene la mayoría de los documentos consultados.

\section{REFERENCIAS CITADAS}

\section{Manuscritos}

Archivo General de la Nación Argentina (AGNA), Buenos Aires.

9-7-7-1. Colonia-Gobierno. Atacama, varios padrones de... 1683-1777.

- Revisita de Atacama de 1683 efectuada por el corregidor Espejo obedeciendo orden del duque de la Palata.

- Revisita de Atacama de 1752 efectuada por el corregidor José Manuel Valdivieso.

13-19-1-1. Sección Colonia, Contaduría, Patrones Potosí, 1791-1792.

- Revisita de Atacama de 1792, efectuada por el subdelegado B. A. de Goyena.

9-30-4-9 (Leg. 33, Exp. 33). Testimonio del expediente formado sobre el empadronamiento en Salta de los indios del partido de Atacama, residentes en aquella jurisdicción.

13-17-2-1. Sección Colonia, Contaduría, Patrones Provincias de Salta, Revisitas de indios 1785-1792.

- Revisita de Salta 1791 (Leg. 2. Lib. 5).

Archivo Nacional de Bolivia (ANB), Sucre.

Catálogo de Minas. Lípez, 1643. II, 14. Ingenio del Rosario de Lípez. Carta de perdón de muerte: Inés Casma, viuda de Martín Tuctipur, y madre de Pedro Viltipoco, difunto, en favor de Martín Chico.
Todos ellos indios Atacama, naturales del pueblo de Sorco, de Atacama La Grande, y empleados en el servicio de este ingenio por la muerte que este último dio al dicho Pedro Viltipoco (ANBEP, Alvarez 1643, Fs. 78-83) Tomo 137.

Fuentes publicadas

ALDUNATE, C. y V. CASTRO, 1981. Las chullpa de Toconce y su relación con el poblamiento altiplánico en el Loa Superior, Período Tardío. Ediciones Kultrún, Santiago.

BEAULIEU, A., 1967. El hábitat humano de la economía agrícola en el oasis de Chiu Chiu. Revista de la Universidad del Norte 4: 81-101.

BOWMAN, I., 1994. Desert trails of Atacama. Special Publication American Geographical Society 5, Nueva York.

- 1942. Los senderos del Desierto de Atacama. Sociedad Chilena de Historia y Geografía, Santiago.

HERNANDEZ, R., 1974. Chiu Chiu: La desintegración de la comunidad tradicional. Antropología 1: 17-33.

HIDALGO, J., 1978. Incidencia de los patrones de poblamiento en el cálculo de la población del Partido de Atacama desde 1752 a 1804. Las revisitas inéditas de 1787, 1792 y 1804. Estudios Atacameños 6: 53-111.

1982. Fases de la rebelión indígena de 1781 en el corregimiento de Atacama y esquema de la inestabilidad política que la precede 1749-1781. Anexo 2: Documentos inéditos contemporáneos. Chungara 9: 192-246. 
KAPROVICKAS, P., 1978. La agricultura prehispánica en la Puna. Actas del V Congreso Nacional de Arqueología Argentina. San Juan.

LOZANO MACHUCA, J., 1965 (1581). Carta del Factor de Potosí Juan Lozano Machuca al virrey del Perú, en donde se describe la provincia de los Lipes. Relaciones geográficas de Indias, Perú, vol. 2. Biblioteca de Autores Españoles 184, Madrid.

MOSTNY, G., F. GELDES, R. GONZALES y F. OBERHAUSER, 1954. Peine, un pueblo atacameño. Publicación 4, Instituto de Geografía, Universidad de Chile, Santiago.

MURRA, J., 1972. El 'control vertical' de un máximo de pisos ecológicos en la economía de las sociedades andinas. En Visita de la Provincia de León de Huánuco en 1562 por Iñigo Ortiz de Zúñiga, vol. 2, pp. 427-476. Universidad Hermilio Valdizán, Huánuco.

1974. Notas del Archivo de Buenos Aires sobre atacameños en Salta. Estudios Atacameños 2: 108-110.

1975. Formaciones económicas y políticas del mundo andino. Instituto de Estudios Peruanos, Lima.
—— 1978 [1955]. La organización económica del Estado inca. México D. F.

— 1983. De la mit'a al Tawantinsuyo: Prestaciones de los grupos étnicos. Chungara 10: 77-94.

NUÑEZ, L., M. V. ZLATAR y P. NUÑEZ, 1975. Relaciones prehistóricas trasandinas entre el Noroeste Argentino y norte chileno (Período Cerámico). Documentos de Trabajo 6: 11-24.

PLATT, T., 1975. Reseña bibliográfica del artículo de Roberto Hernández: Chiu Chiu: La desintegración de la comunidad tradicional. Chungara 5: 153.

SANCHEZ-ALBORNOZ, N., 1978. Indios y tributos en el Alto Perú. Instituto de Estudios Peruanos, Lima.

TARRAGO, M., 1983. La historia de los pueblos circumpuneños en relación con el altiplano y los Andes Meridionales. Estudios Atacameños, este volumen.

VALENZUELA, B., 1970. Epítome etnográfico de la cuenca del río Salado, Provincia de Antofagasta, Chile. Boletín de Prehistoria de Chile 2 (2-3). 